\section{New career for Glomar Explorer?}

The National Science Foundation is looking into the possibility of converting the Central Intelligence Agency's Glomar Explorer into a deep sea drilling vessel. Colin Norman reports from Washington.

WHEN it became known in March last year that the Central Intelligence Agency (CIA) had used a vessel called the Glomar Explorer to scoop bits of a sunken Soviet submarine from the bottom of the Pacific, a number of scientists in the United States expressed concern that the affair could jeopardise flourishing Soviet-American cooperation in deep sea research. A particular worry was that the Soviet Union might sever its ties with the deep sea drilling project (DSDP), a highly successful ocean drilling programme which the National Science Foundation was then endeavouring to turn into an international research enterprise. Ironically, however, the DSDP may turn out to be the chief beneficiary of the CIA's salvage operations.

Last week, the National Science Foundation (NSF) announced that it is studying the possibility of converting the Glomar Explorer into a drilling vessel for possible use in the 1980s. NSF officials, and their clients in many earth science laboratories, are hoping that the Glomar Explorer will provide a cut-price way of carrying out drilling projects which are beyond the capabilities of the present DSDP vessel, the Glomar Challenger. Though it is far from certain that the NSF will be able to get the funds to turn the vessel into a research ship, it is the only use for the ship which is now under serious investigation.

The Glomar Explorer was constructed for the CIA by Global Marine Inc (the same company which built and operates the Glomar Challenger, hence some of the worry about Soviet scientific reaction), for a sum reported to be about $\$ 300$ million. Though publicly billed as a special seabed mining ship built by Howard Hughes, the reclusive billionaire, it was designed for the specific purpose of salvaging a Soviet submarine which sank in about 1,700 feet of water 750 miles north-west of Hawaii in 1968.

The ship recovered bits of the submarine in June 1974-how much is still a matter of some dispute-and when reports of the operation began leaking to the press nine months later, the CIA suddenly found itself with an almost new vessel for which it could

\section{find no further use.}

In the meantime, earth scientists have begun to think about what should follow the present phase of the DSDP. The choice boils down to either dispensing with deep sea drilling entirely or mounting a programme of drilling in presently inaccessible areas such as potential oil-bearing regions, the ocean trenches and under the Arctic sea, a programme which would require a new vessel with greater capabilities than the Glomar Challenger. It would require considerable lifting capacity to handle the long drill strings needed for drilling in ocean trenches, and a thick hull to penetrate the Arctic ice. Moreover, since drilling in the ocean margins entails the risk of striking gas or oil deposits, the vessel would have to be able to handle complex and heavy apparatus to prevent possible blowouts. Construction of such a vessel would probably cost between $\$ 60$ and $\$ 70$ million, a price tag which probably puts it out of the reach of NSF's strained budget.

But Peter Wilkniss, the NSF project director for the DSDP, noted in an interview last week that "when you look at the requirements, it becomes obvious that the Glomar Explorer is almost ideally suited." It is 618 feet long, compared with 400 feet for the Glomar Challenger, and it is capable of lifting about 2,000 tons-more than 10 times the capacity of the Challenger. Moreover, its more powerful engines and greater stability would probably allow it to work in rougher seas.

It is by no means certain, however, that the vessel could be converted
Glomar Explorer easily and cheaply from a salvage ship into a deep sea drilling vessel, and thus NSF has authorised Global Marine to conduct a preliminary study, under a $\$ 75,000$ contract, of the feasibility of converting and operating the Glomar Explorer. The results of that study should be available early next year. In the meantime, the Scripps Institution of Oceanography, which manages the DSDP under a contract from NSF, is looking at the scientific requirements of an expanded drilling programme.

So far, NSF has not given much thought to arrangements for operating the ship if it does decide to acquire and convert it. But, in view of the potentially high costs of operating the vessel-Wilkniss estimates about $\$ 30,000-40,000$ per day, twice that of the Glomar Challenger-there would be obvious advantages in seeking international participation.

In that case, the Glomar Explorer's past associations could pose a problem. Though the Soviet Union did not pull out of the DSDP after the submarine salvage attempt was made known, the operation is said to be a sensitive matter and some ocean researchers privately wonder whether the Soviet Union would participate in a venture for which the Glomar Explorer was a central feature.

It should also be noted that if NSF does decide to follow the present DSDP with a programme of drilling in the ocean trenches and on the continental margins, much of the work would be carried out within the 200-mile economic zones likely to be established as part of a Law of the Sea agreement. That would subject the research to a possible veto by coastal states in whose waters the Glomar Explorer may want to work.

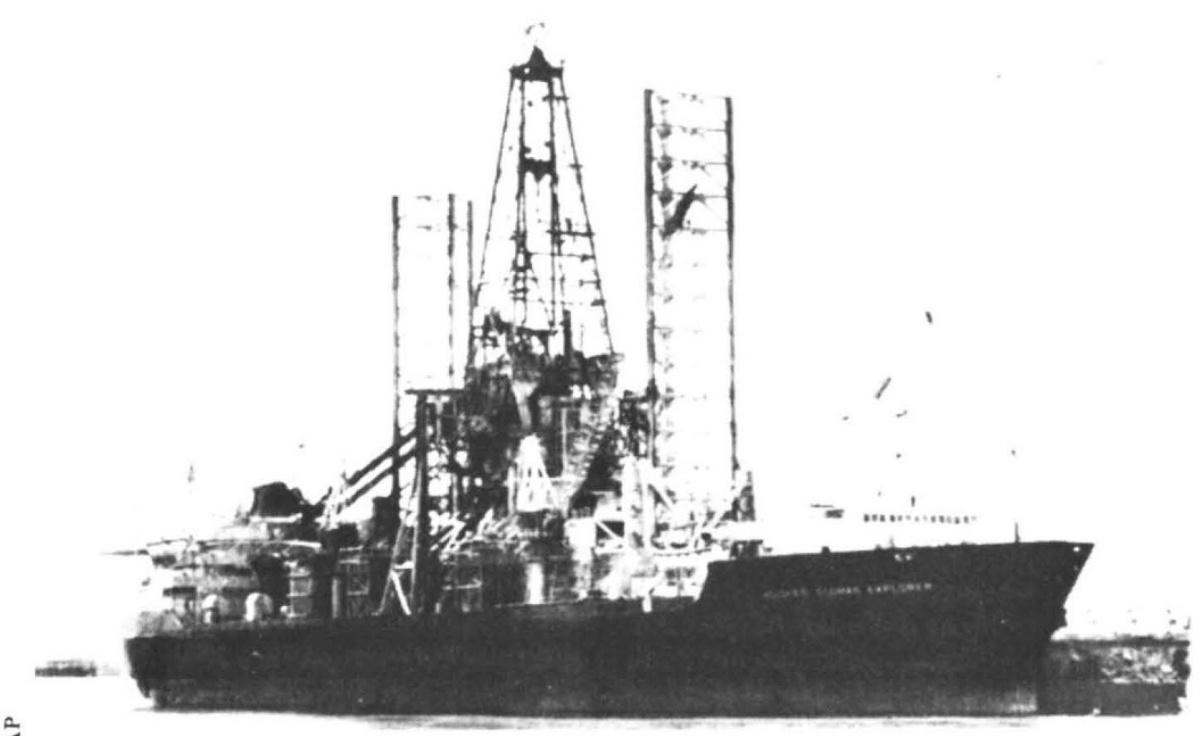

